\title{
Transactive Approach: Explaining Dynamics of Ethnicity and Inter Ethnic Conflicts in Post 1991 Ethiopia
}

\author{
Dagnachew Ayenew Yeshiwas \\ Department of Peace and Development studies, School of Governance, Wollo University, Dessie, Ethiopia \\ Email address: \\ dagnualem@gmail.com, dagnachew.ayenew@yahoo.com \\ To cite this article: \\ Dagnachew Ayenew Yeshiwas. Transactive Approach: Explaining Dynamics of Ethnicity and Inter Ethnic Conflicts in Post 1991 Ethiopia. \\ International Journal of Education, Culture and Society. Vol. 3, No. 4, 2018, pp. 68-77. doi: 10.11648/j.ijecs.20180304.11
}

Received: October 4, 2018; Accepted: October 22, 2018; Published: November 12, 2018

\begin{abstract}
Indeed, Ethiopia is a heterogeneous state. And the successive regimes have implemented their respective strategies towards diversity that left its own good and bad legacies. Since 1991, the state has unprecedentedly experimented ethnic federalism as a means to accommodate ethnic diversity. Therefore, this study has explained dynamics of ethnicity and ethnic relations since the inception of ethnic federalism. The paper employs qualitative research design and draws heavily on secondary sources, including books, journals, researches and reports of various institutions. Nevertheless, the data collected through in depth interview, observation, social media discourses is also consulted and analysed thematically. Theoretically, transactive approach as alternative explanation to ethnicity and ethnic conflicts in Ethiopia is discussed as part of the analysis in various sections. The paper demonstrates that in Ethiopia; ethnicity is neither blindly primordial nor completely manipulable. It is thus, a matter of categorical ascription and social organization in terms of culture and history, similarity and difference. Ethnic conflict is not also merely out of primordial differences or mobilization by ethnic entrepreneurs. But it is the result of feelings and sentiments in which members of a particular group develop as they interact and compare their positions with other ethnic groups. In doing this, the finding of this study bridges the extreme schools of thought in ethnicity: primordialism and instrumentalism.
\end{abstract}

Keywords: Ethnicity, Ethnic Conflict, Ethnic Federalism, Transactive, Primordial, Instrumental

\section{Introduction}

Ethiopia is a multi-ethnic state endowed with diversified culture, language, faith, religion and long history of state hood. Therefore, successive regimes in itshistory have implemented different strategies in dealing todiversities. For instance, during the imperial regime, 'nation building' was the state policy in treating ethnic diversity. The objective was cultivating Ethiopian nationalism through assimilating various groups in to the dominant Abyssinian culture [1]. Thus, in imperial Ethiopia; the issue of ethnic diversity was a taboo.

This centralist policy of the state with the then time global political wave on self determination make questions of nation nationalities inevitable in the country. As such, during the 1960s and 1970s ESM ${ }^{1}$ which was evangelized by Marxism philosophy - ethnic diversity and the right of nation

1Ethiopian Student Movement nationalities become major agenda of public discourse. During the radical student movement of the 1960's and 70's, the overall discourse was about Marxist- Leninist ideas of 'nationalities question' and 'right to self determination up to secession'. As Markakis noted, the movement particularly the release of an article on nationality question by WalelignMekonnen in 1969 has resoundingly broken the taboo [2].

Accordingly, the nationality question propagated by ESM has seriously challenged assimilationist nation building strategy of the regime and paved the way for political instability emanated from ideological and identity differences prevailed in the state for the next two decades. Moreover, the movement has triggered the 1974 Ethiopian revolution and brought the military council (dergue) in to political power. The Derguewhich had neither political knowledge nor experience to handle contradictory issues of the state during the time provides a chance for students to brought 'nationality question' in to the political spectrum. As Hizkias 
hasreported, "the radical student leaders were brought in to the government, where they became the revolution's advisers and ideological leaders. Those students then had the opportunity to make nationalities question a national agenda [3 p. 9]."

However, soldiers' understanding of national contradiction is limited to cultural rights [2]. The principle of 'indivisibility of Ethiopian unity' remained as a motto 'ethiopiatikdem'(literally means Ethiopia first). This in turn led to the rise and growth of armed struggles throughout the state throughbearing their respective ethnic names (EPLF, TPLF, WSLF, OLF ${ }^{2}$.). Therefore, political demands of national struggles continued to undermine both the unity of Ethiopia and legitimacy of the regime. Then, in 1991, the Dergue was overthrown; EPLFand EPRDF ${ }^{3}$ (TPLF) controlled Asmara and Addis Ababa respectively. Eritrea became formally an independent sovereign state in 1993.

In 1991, since political power is captured by legacies of ESM, making ethnic diversity a national agenda was not challenging. As soon as they took power, ethnic politics is declared as a panacea of political instability, ethnic conflict and past injustice as well as an instrument to protect the right of ethnic groups [4]. The constitution of the state introduced a new political arrangement termed as 'ethnic federalism' in which the rights of nation nationalities and peoples (ethnic groups) to self determination up to secession' is recognized $\left(\mathrm{FDRE}^{4}, 1995\right)$. So as to accomplish this, nine regional states are established based on ethnic line.

Since the day of its inception, ethnic federalism and ethnicity in Ethiopia have been hosting polarized academic and political discourses [5]. Proponents of ethnic federalism praised the framers of ethnic federalism as there had not been other option left in Ethiopia for both practical as well as conceptual reasons $[6,4]$. Ethnic federalism is successful in ending the deadliest protracted conflicts and maintaining the unity of the state $[6,4,7,2]$. To the opposite, others argue the new arrangement has fuelled new forms of ethnic conflicts and encouraging disintegration than stabilizing and preserving the unity of the country $[8,9,3,10]$.

Empirically, despite the institutionalization of ethnic federalism as a panacea for conflicts prevailed in the state, the recent condition of intra and inter ethnic affairs appear to challenge the long held interdependence and togetherness of the people in the country. Now a day people in different parts of the country are suffering from violent conflicts emanated from human fault lines, ethnicity and religion and ethnic based attacks. The unity of the state is still challenged by inter ethnic affairs. But, what are the real causes behind this? Is ethnic federalism source of all evils undergoing in the period? Is ethnic diversity by itself source of conflict? Addressing these questions will provide clear picture of dynamics of ethnic conflicts in the period.

2Eritrean People's Liberation Front, Tigrean Peoples Liberation Front, Western Somali Liberation Front and Oromo Liberation Front respectively

3Ethiopian People Revolutionary Democratic Front

4 Federal Democratic Republic of Ethiopia Constitution (1995) in federal negaritGazeta.First year number one.
Following the federalization process, ethnicity has become salient feature of social and political fabric of the people. Ethnicity is not a problem by itself but the problem is the way it has been introduced in to Ethiopian politics. In most cases including FDRE constitution, ethnicity has been defined as either membership to a group of people which share primordial elements, such as common language, common ancestry, and feeling of solidarity $[11,12]$. Or it is membership to imagined communities created and manipulated by ethnic entrepreneurs [12, 13]. But, both arguments are against social structure and historical context of the statefor reasons discussed later. For example, Asnake has stated with the attempt of the government to define ethnicity based on essentialist primordial factors in Ethiopia; there appear various ethnic conflicts in post 1991 period [8]. So, Is there any alternative approach left to explain ethnicity and ethnic conflict in Ethiopia? Hence, this paper investigates dynamics of ethnicity and ethnic conflicts in post 1991 Ethiopia with a new approach to the subject transactive approach.

\section{Methodology of the Study}

This paper has employed qualitative research approach. The rationale for the selection of the qualitative research approach is due to the fact the conceptual issues to be investigated require a holistic qualitative data and discussion. The paper draws heavily on secondary sources, including books, journals, researches and reports of various institutions. Nevertheless, the data collected from interview, observation and social media discourse are also consulted. The data collected is analysed thematically, transactive approach as alternative explanation to ethnicity and ethnic conflicts in Ethiopia is discussed as part of the analysis in various sections.

\section{Ethnicity and Ethnic Conflict: Theoretical Approaches}

In discourses of ethnicity, perhaps the most serious deficiency is lack of a uniform criterion to define it. For some, ethnicity is assessed in termsof race, in others as a language still in other cases religious difference become vital tool to define it. Hizkias has argued that many concepts such as, nationality, tribe, and clan are used interchangeably with that of ethnic group, and it is very difficult to distinguish them [3]. Thus, as Tronvol describes, still there is no common definition of ethnicity which can be used unanimously [13]. Regarding this, Merera stated that ethnicity and nationalism are the most elusive terms without universally applicable definitions; rather they are defined in relation to the specific ideology and the given context [14]. Perhaps, variations in the definition and understanding of ethnicity are emerged from the following three theoretical perspectives. 


\subsection{Conceptualising Ethnicity: Contending Approaches}

\section{A) Primordial Approach}

Primordialism is the oldest of three categories dates back to $1950 \mathrm{~s}$ and $1960 \mathrm{~s}$. Primordialists in their analysis claim, ethnicity refers to the condition of belonging to a certaingroup based on common primordial ties such as kinship, language, culture, customs and religion. As Tronvol and Asefastated, ethnicity is an inherent and natural aspect of human existence which is endowed to individuals by an accident of birth from their parents $[13,15]$. Therefore, for primordialists "ethnicity is fixed at birthethnic identification is based on deep, 'primordial' attachments to a group or culture" [16]. At birth, one become a member of a particular group and will never be member of another group. One is always and invariably Amhara, Oromo, Gumuz or Agew [17].

Moreover, Primordialists argued that inherently ethnicity is the generic cause of conflict [18]. So, ethnicconflicts are based on ancient hatreds and ethnic differencesamong groups fighting and therefore, no explanation can be done about it $[11,19]$. The argument seems ethnic conflict is one aspect of ethnic heterogeneity as ethnicity is an aspect of human existence. But, there are heterogeneous states which are peaceful and homogenous states with conflict as well. Groups come in to violent conflict at a time and peaceful in the other days. So, ethnicity is not inherently problematic.

Another critic of the approach is that it does not recognize that ethnic ties may have other social origin and shaped by historical contexts. Primordilist perspective is criticizedfor failure to recognize the dynamic nature of ethnic identity. It means new ethnic identities can be constructed with changes of context [20]. Hyden also argues primordialism is static and a historic because it is ignorant to explore other sources where ethnic attachments can emanate from [21].

\section{B) Instrumentalist Approach}

Instrumentalists treat ethnic identity as a resource to materialize one's economic or political goods [13]. Ethnicity may appear in social and political actions to achieve higher ends. According to [16] ethnicity, for instrumentalists is 'based on people's 'historical' and 'symbolic' memory, it is something created, used and exploited by leaders... in the pragmatic pursuit of their own interests". Therefore, ethnicity is not independent from competitions in political process. It is just like membership to political parties or interest groups [11].

Thus, for instrumentalists, ethnic conflict is not more than hiddenclass conflict; ethnicity is not the true generative cause of any social phenomenon, even though it often may appear to be [11]. This argument is based on the premise of utilitarianism, ethnicity is treated as exogenous variable one does not need to be explained (Hyden, 2006:188). It means individuals are ready to make cultural trade-off in order to achieve tangible gains. It ignores the role of socialization plays in fostering affection and emotional attributes of ethnicity in which people may not ready to scarify. Thus, as Hyden has discussed for instrumentalists cultural tradition as a variable disappears from the calculation in ethnicity and ethnic conflict [21].

\section{C) Transactive Approach}

Transactive approach presumes that ethnicity is the result of broad social interactions across group boundaries. As Eriksen argued:

For ethnicity to come about, the groups must have aminimum of contactwith each other, and they must entertain ideas ofeach other as being culturally different from themselves. If theseconditions are not fulfilled, there is no ethnicity, for ethnicity isessentially an aspect of a relationship, not a property of a group [22 p. 12].

Similarly, Barth states, culture and its attributes are insufficient to conceptualize ethnicity, rather ethnicity and ethnic group is a matter of group relation through which boundaries are created by mutual understanding of groups [23]. This entails that; ethnicity is not an aspect of culture but a social organization. The point of transactive approach is that ethnic boundary is maintained not for cultural reason but due to historical, social and political contexts of the interaction. According to Hyden;

An ethnic group is constituted not because of some essentialist factors, but because of having interacted over time with other similar groups. Members of the group are social actors capable of adapting their identities to changes in circumstances. Some may even transcend existing boundaries and change their identities by moving from one ethnic group to the other [21 p. 188).

Therefore, ethnicity is a matter of categorical ascription, as Barth notes, "Ethnic groups are categories of ascription and identification by the actors themselves...." [23 p. 10]. But, it is not also only identification by members of group but also it needs recognition from others. Interestingly, beyond instrumentalist approach, Horowitz adds the role of affective and emotional attribute in shaping ethnicity and ethnic relations [21 pp. 188-189]. Thus, ethnicity is neither blindly primordial nor easily manipulable. Jenkins rightly explains, 'there are limits to plasticity of ethnicity, as well as its fixity and solidity, is the founding premise for the development of an understanding of ethnicity...' [24].

\subsection{Inter-Ethnic Conflicts: Why Transactive Approach}

Like ethnicity, defining ethnic conflict is also a challenging task. However, for the purpose of this study, it could be conceptualized as a conflict where "the goals of at least one conflict party are defined in (exclusively) ethnic terms, and in which the primary fault line of confrontation is one of ethnic distinction" [19 p. 2). It can be either violent or non violent, covert or overt [32]. Nonetheless, the conflict is an ethnic when:

At least one of the conflict parties will explain its dissatisfaction inethnic terms - that is, one party to the conflict will claim that itsdistinct ethnic identity is the reason why its members cannot realizetheir interest, why they do not have the same rights, or why theirclaims are not satisfied. Thus ethnic conflicts are a form of groupconflict in which at least one of the parties interprets the conflict, itscauses and 
potential remedies along an actually existing or perceiveddiscriminating ethnic divide [6 p. 2).

Transactive approach claims, ethnic conflicts are neither merely emanated from the pursuit of material advantages nor do they stem from irreconcilable primordial factors. Ethnic conflict, however, is the result of feelings and sentiments in which members of a particular group develop as they interact and compare their positions with other ethnic groups [21p. 189]. The comparison brings a sense of worth - inferior or superior position in contrast to referent groups - members of a group may felt relatively deprived of socio-economic and political benefits. As scholars of conflict studies suggest relative deprivation is among the major sources of conflict [27]. Deprivation can be political, economic, horizontal (between groups) or longitudinal (for particular group across time) [20 p. 4].

As Freeman argued that a man can look at his rich neighbour and realize his own poverty or days when he himself was wealthy. The analogy works across ethnic groups at large $[20$ p. 5]. Hence, when the line of deprivation (actual or perceived) coincides with ethnic lines, it breeds suitable environment for mobilization of the mass for violence. Nevertheless, Freeman argues a conflict will be transformed in to violence after the cost-benefit analysis of violence being the only remedy for the problem at hand [20]. Accordingly, in explaining ethnicity and ethnic conflicts, the transactive approach goes beyond the primordialist approach because it recognizes the outcome of social interactions. It also includes the role that spontaneous and informal behaviour and institutions play in determining ethnicity and ethnic conflicts beyond instrumentalist view.

Thus, transactive approach best fits with the main thesis of this study: explaining dynamics ofethnicity and inter ethnic conflicts in post 1991 Ethiopia. It does not mean, the remaining two approaches are not use full or transactive approach is more use full. It is rather that the selection of one approach from others is based on the existing context of the country. Accordingly, at least there are four reasons ${ }^{5}$ to study ethnicity and ethnic conflict based on transactive approach in Ethiopia.

The first reason is changes brought by ethnic federalism. In the last two decades, it is observed that the salience of ethnicity in Ethiopian politics led to both necessary and unnecessary competition in various activities among ethnic groups of the country. As Hyden notes, "with growing competition groups are becoming more aware of their relative worth and tension among them increases" [21 p. 189].

The second reason is that the existing market economic policy of the state with uneven distribution of natural resources in the country leads to high level of mobility from one corner of the state to another. It is observed that there is high migration of people in the state in the period than ever. This may have an impact on the effectiveness of indigenous

5The first three are adapted from Hyden (2006), in his analysis of ethnicity and ethnic conflict in Africa to the context of Ethiopia. (hosting) groups to maintain ethnic boundaries. This led to shift of group identities from one to another.

The third reason is the relatively small size of most ethnic groups in the country. Strategies of boundary maintenance in those groups are likely to weaken, because they have to compete with others. Therefore, building socio-economic or political alliance with others is justifiable. The same is true for larger groups. As such, ethnic boundaries are becoming open for inter marriage and other forms of alliance.

The last reason for studying ethnicity in transactive approach is that ethnic cleavages in Ethiopia are not as such sharp. There has been greater inter marriage, assimilation and adoption across ethnic groups. Cleavages among groups are not clear cutting. It is rather, cross cutting in terms of religion, similar culture even language. People are/were open to the influence of others; ethnic relations are/ were fluid and dynamic.

In this regard, Asnake stated that with the attempt of the government to define ethnic identity based on essentialist primordial factors, there appear various ethnic conflicts in post 1991 period [26]. This is because the identity of many minority groups is controversial. It is, therefore, misleading to argue ethnicity in Ethiopia is based on primordial ties or mere instrument of other ends.

\section{Dynamics of Ethnicity and Inter Ethnic Conflicts in Ethiopia}

\subsection{Ethnicity in Ethiopian History: Source of Harmony or Hostility}

Regarding the nature of inter ethnic relations in the history of Ethiopia, there are polarized views from prominent scholars. Merera represented the history of Ethiopia as the history of conflict [26]. In another extreme, Hizikias stated that "the norm in the country has been ethnic coexistence rather than ethnic warfare" [3 p. 6]. The latter argues, the so called 'ethnic conflict in the past Ethiopia was not more than a conflict which appears between elites from different ethnic back ground. It means there is consensus among scholars on the existence of conflict rather their difference is on the role of ethnicity in the course of violent conflicts. And when someone attempts to puzzle out the difference through looking thoroughly their claims and counter claims, the problem is attributable to variations in conceptual understandings of ethnicity and ethnic conflict emanated from the earlier theoretical perspectives.

Accordingly, the first argument articulates ethnicity as major source of contention in the history of the state $[4,2$, 32]; whereas the other extreme [8, 28, 3] argued the conflict in the country gives sound meaning if it is explained in terms of socio- economic marginalization than ethnicity. In the word of Hizikias, the conflict has been 'elite driven conflict', not a conflict emanated from mere ethnic hatred and animosities [3]. The first analysis is inclined to the primordialist perspective which argues ethnic difference is essentially source of conflict among groups. Whereas the 
second explanation is an instrumentalist argument; ethnicity is totally superficial in ethnic conflict of the state but manipulated for economic and political motives of elites. However, both arguments are unconvincing though not problematic. In spite of its influence in the course of group conflicts, in Ethiopia ethnicity is neither inherently problematic nor superficial. This paper claimed that ethnic conflicts in the country were/are results of group's comparison against the other in terms of economic, political and social positions.

Regarding the political history of Ethiopia, analysts of Ethiopian conflicts are obsessed to cite the event (expansion of Menelik II) which took place during the $19^{\text {th }}$ century in the country. They stated that the years following the victory of emperor Menelik II on newly occupied territories were characterized by land encroachment, and imposition of language, culture and religion of the Amhara [1 p. 44-45]. They assume ethnic diversity following the expansion brought distasteful ethnic relations between ethnic groups, particularly between Amhara and other nationalities.

Markakis notes, "The imperial state was founded on explosive conjunction of antagonistic class and ethnic divisions that made it inherently unstable" [2 p. 7]. Similarly, Endrias while discussing about the chief causes of 1960s and 70 s resistant movements, he concluded that, "nationalist struggle was against the suppression of nationalities and regional identities by people from other nationalities" (emphasis mine) [4 p. 10]. Thus, for them, in Ethiopia ethnicity has been a problem resulted from Amhara domination over other ethnic groups of the country. Markakis further notes, "Ethnicity was the political essence of the imperial state, where the distribution of power was based on ethnic calculus that gave a near monopoly to Amhara ruling classes" [2 p. 8].

To the opposite, Clapham argued, "economic marginalization provides a better explanation than ethnicity, and political exclusion even economic exploitation to the incidence of insurgencies" [28 p. 404]. Abbink has also stated that the root causes of conflicts during the previous regimes were marginality in all spheres due to geographical remoteness and less valuable resources [8]. Abbink further argued that if the problem was ethnicity, Arsi Oromo (violently subdued by Menelik II) would be the first to fight against the centre, but Tigray the centre of Abyssinian civilization was the first not Arsi Oromo [8 p. 165]. On his part, Hizikias claimed that the so called ethnic conflict has not been emerged from ethnic animosity [3]. According to Hizkias conflicts before institutionalization of federalism were instigated by elites from different ethnic backgrounds (Ibid).

However, meaning of ethnic conflict for Hizkias is at first problematic, he argues a conflict is an ethnic conflict if it emerges from mere ethnic animosity and hatred, and ended with ethnic cleansing and genocide. However, this paper argues any conflict is ethnic conflict, where at least one conflicting party claims the cause for the conflict and remedies are related with ethnic fault lines [19]. Hence, in the past Ethiopia, ethnic conflict has been the norm of the state but it was not emanated because the state is heterogeneous. It is to mean that ethnic conflicts were not erupted from mere ethnic difference, animosity or hatred. The chief source of ethnic conflict in the history of the state was real/perceived illegitimate socio-economic and political boundaries between ethnic identities. During the imperial regime, at least nationalist armed struggles fighting against the central government claimed their source of hostility was exclusion from key activities of the state because of their ethnic identity $[4,14]$. As [19] stated when at least one of conflicting parties explains its dissatisfaction in ethnic terms, the conflict is ethnic conflict. In this regard, the following data also shows real variation in opportunities of education:

In the class entering university in 1968, Amharigna speakers accounted for 55.5 percent, Tigray speakers (including Eritreans) 23.5 percent, Oromo 10.4 percent, Gurage 2.3 percent, Aderi 1.7 percent (Cooper \& King, 1976, p.273). At the Department of Ethiopian Languages, Haile Selassie I University, only Geez and Amharigna were studied (2 p. 3).

Abbink has also reported:

We know the actual ethnic diversity in Ethiopia, and the enduring problems of ethno-regional disparities in education, infrastructure, development and representationin leading administrative positions at the level of the central state. Both the large Oromo population and the many minority groups in Ethiopia, iflooked at proportionally, were underrepresented in all major domains. Many groups which were incorporated or conquered by Minilik II in the late 19thCentury remained marginal to the polity, the economy and the exercise of administration [8 p.164].

Therefore in the pre 1991 Ethiopia, it can be concluded that there was feeling of relative deprivation which was coincided with ethnic lines. Freeman argues, when actual or perceived deprivation corresponds with ethnic lines, it provides an opportunity for elites to mobilize the mass [20]. But, this is not to mean that elites were easily mobilizing the mass members of a group for violence based on mere identity difference. For instance, Vaughan notes '... in mobilizing peasant support [TPLF and its Coalitions], they suggest that nationality was less a primary contradiction in Ethiopia, than the most effective means of mobilizing the population to combat uneven development' [24 p.118]. Thus, elites were manipulating feelings of relative deprivation/exclusion than ethnicity.

This paper also argues that violent ethnic conflicts in history of Ethiopia were not consequences of mobilization. Contradiction between ethnic identities will not be transformed in to violence through mere mobilization but after rationalizing the cost and benefit of employing violence as a solution to the contradiction by members of the group at large. On this, Vaughan stated that forging popular consensus among Tigrians against the central state took 10 years for TPLF [24 p. 118). This demonstrates that ethnicity is not easily manipulable by political elites in the way instrumentalists argue on it. Hence, in history of Ethiopia, 
fundamental source of ethnic conflict has been emerged from feelings of comparisons of one ethnic group with other referent groups. It was not the result of ethnic heterogeneity or mobilization of elites.

\subsection{New Trends onEthnicity and Inter-Ethnic Conflicts in Post 1991 Ethiopia}

\subsubsection{Ethnicity}

As it has been discussed before, in most cases, ethnicity is defined as either membership to a group of people which share primordial elements, such as common language, common ancestry, and feeling of solidarity. Or it is membership to imagined community created and manipulated by ethnic entrepreneurs. But, when someone deeply observes dynamics of ethnicity in Ethiopia in the last two decades, it would be clear that the two dominant schools on ethnicity are unable to provide complete explanation on the subject.

In Ethiopia, dynamics of ethnicity is hardly explained by primordial arguments which claim ethnicity is static based on essentialist attributes - ethnicity is fixed. For instance, during the transitional period there were only 63 recognized ethnic groups, but now a time official reports revealed that the state hosts more than 80 ethnic groups [29 p. 62]. From where do these 17 ethnic groups appear?Moreover, in post 1991, five ethnic groups are deleted and other new six ethnic identities are newly registered in to the national statistical census of the country [29 p. 62]. In the period, Silte and Kimant are also recognized as having their own distinct ethnic identity different from Gurage and Amhara respectively. In Metekel, Kumpal that was identified as different ethnic category before 1991 is now categorized under the family of AgewAwi [17]. Similarly, Gumuz, before 1991 called themselves and by others Shanqila ${ }^{6}$, but during the field work, no Gumuz informant mentions the term as their identity marker. Thus, ethnicity in Ethiopia is dynamic in which members of the group adapt themselves to changing circumstance.

The ongoing debate on the existence of Amhara ethnic identity has also been attracting scholars. Though it is contestable until very recently, Amhara people are one of ethnic groups in Ethiopia in which a regional state is designated by their name. However, it is hard to say members of the group share the aforementioned primordial ties. Tegegne stated;

The Amhara does not possess what usually referred as objective ethnic marker: common ancestry, territory, religion, and shared experience except the language. The Amhara have no common claims to a common ancestry. They do not share the sentiments and they have no mutual interest understandings [24 p. 120].

According to studies conducted so far, members of the Amhara have been identifying themselves by regional cleavage identities; Gondere, Gojjame, Shewe, Wolloye [3, $30,10]$. Moreover, Hizkias has reported that one regional

6Now a time, the term is considered as derogatory that represents the Gumuzas despised ethnic group. cleavage was waging war against another in aligning with other ethnic groups such as Tigre, Gurage and Oromo [3]. Wubshet has also noted "after the battle of Segele" the relation between people of Shewa and Wollo had been as enemies to each other or at least as people from different ethnic identities" [29 p. 67]. But, now a time the rise of Amhara nationalism is becoming the predominant point of discussion among members of its regional cleavages and scholars. It can be argued that a strong sentiment of belongingness and membership to Amhara ethnic identity is being developed. How can primordial understanding explain the rise of the new Amhara nationalism?

The Ethiopian experience of ethnicity has also demonstrated, having similar language and culture do not necessarily determine group identity. In the case of Kimant, for example, members of the group are speaking Amharic language and share similar cultural practices with other Amhara people living in Gonder. However, they claim for their distinct identity from the rest of Amhara and the regional government has also recognized it. Spokesman of the regional state council during the time, AtoYalew Abate $\left(04 / 07 / 07 \mathrm{E} . \mathrm{c}^{8}\right)$ said that "particularly people of LayArmacho and Chilga district identified themselves as Kimant and the remaining neighbouring people are again called them Kimants, thus their ethnic identity is Kimant not Amhara" [29 p. 66]. Thus, they are now recognized as people with having their own ethnic identity. Regarding this, Barth argued that "Ethnic groups are categories of ascription and identification by the actors themselves...." [23 p. 10]. In ethnicity, others ascription is not also enough. For example, the attempt of creating a single language identity of WoGaGoDa ${ }^{9}$ out of four ethnic groups has caused destruction of property and claims to numerous lives following violent ethnic conflict among groups [26].

Ethnicity in Ethiopia is not also something created and manipulated by elites; called themselves representatives of the group. The case of Silte makes the argument clearly plausible. In 1999 a conference was held at Butajira arranged by the government of SNNPRS ${ }^{10}$ with 961 Silte speaking representatives. The conference had the aim to decide whether Silte is different from Gurage or not. However, in the conference no one has supported the claim of being different ethnic identity. Later, a referendum was conducted; among 421,188 participants, 416,481 have voted for the distinct identity of Silte. It shows how the interest of the mass has reversed the decision of the so called 'ethnic representatives/elites'. The case of WoGaGoDa is also empirical example for ethnicity in Ethiopia cannot be explained by instrumentalist perspective.

Thus, from the above discussion, it can be concluded that

7The battle of Segele was a victory for the supporters of Empress Zewditu (from Shawa) over those Iyasu v of Ethiopia (from Wollo) fought on October 27, 1916. 8Ethiopian Calendar

9 WoGaGoDa was a project of government to create language of instruction out of Wolayita, Gamo, Gofa, and Dawuro, but the project terminated particularly with resistance from people of Wolayita(Asnake, 2004:57).

10South Nation Nationalities and Peoples Regional State 
ethnicity in Ethiopia is neither necessarily sprung from fixed primordial ties nor a mere means to further economic and political interests. In this regard, Jenkins has explained the subject convincingly;

That there are limits to plasticity of ethnicity, as well as its fixity and solidity, is the founding premise for the development of an understanding of ethnicity which permits us to appreciate that although it is imagined, it is not imaginary; to acknowledge its antiquity as well as its modernity. Rethinking demands that we should strike to a balanced view of authenticity of ethnic attachments, somewhere between irresistible emotion and utter cynicism, neither blindly primordial nor completely manipulable, ethnicity and its allotropes are principles of collective identification and social organization in terms of culture and history, similarity and difference, that show little signs of withering away (24 p. 117).

This paper argued that either primordial or instrumental schools could not completely explain the dynamics of ethnicity in Ethiopia. So, transactive approach appears convincing in explaining and analysing dynamics of ethnicity in Ethiopia. As it has been discussed, ethnicity in Ethiopia is a matter of categorical ascription, and shaped by historical, social and political contexts of relational space. Ethnicity is not constituted for some essentialist factors but from having interacted over time. People are adapting their identities to changes in circumstance; some may even transcend existing boundaries and shift their identities.

Hence, ethnicity in Ethiopia is an enormously complex concept. No ethnic entity has been untouched by others. Groups in existence in the twentieth century are biological and social amalgams of several preexisting entities. The ingredients are often discernible only by inference, particularly if the mixing took place long ago. Nonetheless, such mixing led to the formation of groups that think of themselves and are considered by others as different.

\subsubsection{Ethnic Federalism and Inter Ethnic Conflicts}

\section{(i) Debates on Ethnic Federalism}

Ethiopian federalism has been hosting polarized academic and political discourses since the day of its inception. Listing conferences held on ethnic federalism is a challenging task. Nevertheless, ideological and practical reviews on the subject demonstrated the existence of polarized debate - 'meta conflict' among elites [18]. The conflict is between three groups. Proponents of ethnic federalism (e.g Mengesha, 2008; Endrias, 2003; Gebreab, 2003; Markakis, 2003), and opponents (e.g Hizkias, 1996; Mesfin, 2003; Alemante, 2003; Abbink, 1997) are some among others. In between the two extremes, there is a group which accepts ethnic federalism in principle but blames framers for the discrepancy between the policy and practice (e.g Merera, 2003 and Asefa, 2010).

Among the proponents, Mengesha and Endrias praised the framers of ethnic federalism as there had not been other option left in Ethiopia for both practical as well as conceptual reasons $[4,6]$. According to them, Dergue was ousted from power by nationalist struggles with political demands either for independence or self rule such as EPLF, TPLF, OLF, WSLF and others. Participants of peace and democracy conference ${ }^{11}$ were also predominantly 'nationalist organizations' in need of self determination. Therefore, Endrias has concluded that "the history and identity of protagonists in the wake of victory over tyranny thus explains why ethnic federalism proved to be a decisive political instrument in Ethiopia's transition to democracy" [4 p. 17].

They are also arguing on its success, Endrias forcefully pointed out, "Ethnic federalism concluded protracted civil strife fuelled or exacerbated by ethnic cleavage and conflict" [4 p. 3]. Mengesha has also stated that through recognizing and empowering minorities, ethnic federalism has ended the hegemony of one ethnic group which in turn creates social cohesion and national integrity; this enables it to end decades of civil war in Ethiopian history [6 pp. 172-175]. Thus, for proponents, ethnic federalism was right in its rational and successful in achieving its objective.

On the other hand, various elites argue against the policy and practice of ethnic federalism. Their critics begins, first Ethiopia had not experience the so called ethnic conflict. As it is discussed before, they argue, the conflict was rather between central government and insurgencies just bearing ethnic names [3]. Chief sources of conflict were socio economic marginalization not nationality question [28]. Thus, for them, self determination and independence were not the right solutions [8, 9]. According to their argument, institutionalization of ethnic federalism fuels new forms of ethnic conflicts which are strange to the state. Bloody conflicts over economic and political resources, claim of territories, and exclusion of regional minorities becomes manifestation of the post 1991 Ethiopia which was uncommon in history $[9,22]$. Thus, the arrangement fuels ethnic conflicts and encouraging disintegration than stabilizing and maintaining the unity of the state.

To the remaining others, Ethiopia's federalism is the right path. But, they criticize lack of real commitment of the ruling party for the promises of the constitution; right to self determination and secession [31, 32]. For them, discrepancies between the theory of federalism and the practice at the ground are major sources of violent conflicts in which the country has been experiencing $[31,32]$.

\section{(ii) Ethnic Conflicts in Post 1991 Ethiopia}

The discussion conducted so far revealed that there are polarized understandings on the implication of ethnic federalism on interethnic conflicts of the state. On the one hand, Ethnic federalism is praised for ending protracted civil war prevailed in the state in pre 1991 period [2, 4, 6, 7]. It is claimed that in post federal Ethiopia, ethnic relations are based on equality and cultural pluralism. The fear of opponents to the dismemberment of Ethiopia was also neutralized by the participation of all ethnic groups from corner to corner during Ethio-Eritrean war (1998-2000) [6].

11It was a conference held in July 1991 at Addis Ababa during the transitional period of Ethiopia 
On the other hand, the new state policy is blamed as source of all evils that are going on within the state in post 1991 Ethiopia [9, 3, 10]. Accordingly, in post 1991, Eritrea has seceded from Ethiopia and violent ethnic conflicts are still challenging the unity of the state. Empirically, Ethiopia has also been experiencing the most deadly inter ethnic conflicts since the day of inception of ethnic federalism than ever. Ethnic conflicts between Guji and Gedeo, Amhara and Tigray, Sidama and Wolayita, Wolayita and Gamo, Amhara and kimant, Afar and Issa, Somali and Oromo are among others. The period has also witnessed ethnic based violence in many parts of the state; attacks over Amhara in Arbagugu and Wollega, attacks over Agew and Amhara in Metekel, the recent attack on Gamo in Burayu can be mentioned among others. But, is ethnic federalism the real cause behind such evils?

As the data from fieldwork and the studies conducted so far revealed, Ethnic federalism is only a single cause among multifaceted major factors of inter ethnic conflicts and ethnic based violence undergoing in the state. But, as Asnake has noted these factors for ethnic violence and conflicts in the period are accompanied by federalization process of the state [26]. Thus, the new political arrangement can be taken as an aggravating and complicating factor behind other issues in the course of ethnic conflicts. As such, factors behind such evils can be categorized in to the following three major categories.

A. Relative deprivation

Relative deprivation is feeling of being excluded from social, economic and political benefits in contrast to other referent groups [20]. And when this feeling coincides with ethnic lines, it becomes a cause for ethnic conflicts [20]. The study conducted by Dagnachew has identified relative deprivation as major cause of inter ethnic conflict in Metekel zone [12]. This is because, in the last two decades, ethnicity has become essential point of explanation in social and political fabric of citizens - burdens and benefits are explained based on ethnicity. Therefore, if anybody is excluded from benefits, it is perceived as his/her ethnic identity is a cause for exclusion.

Accordingly, in the last two decades, Ethiopia has been ruled by TPLF (EPRDF) which is believed to favourTigreans against other member ethnic groups of the state. Key political positions, economic and financial institutions, military and security offices were predominantly stuffed and operated by Tigreans. This angered other ethnic groups particularly the two dominant ethnic groups in a state - Amhara and Oromo. As such, in the last three years the state has experienced violent popular protests and uprisings against the ruling party and Tigreans, people perceived to be long favoured by TPLF. The uprisings led to the coalition of Amhara and Oromo elites and the end of TPLF dominance among member parties of EPRDF ${ }^{12}$. The coming of the new PM Abiy Ahmed is also

12EPRDF is a ruling party in Ethiopia since 1991 that compose TPLF (Tigrean Liberation Front), ANDM/ADP (Amhara National Democratic Movement/ Amhara Democratic Party), OPDO/ODP (Oromo People Democratic Organization/Oromo Democratic Party), SPDM (Southern People Democratic associated with this movement of the youth from these two largest ethnic groups.

Therefore, feeling of relative deprivation can be cited as the major factor behind ethnic conflicts in Ethiopia, particularly between Tigreans and others. Still, the state cannot resolve problems associated with equal sharing of political and economic resources. TPLF did not take a lesson from the past system that it was organized (and claim) to fight against unfair distribution of resources and political positions. It means, in post 1991 period deprivation of groups in contrast to other referent groups remains as burden for the state in the effort of maintaining peace, stability and democracy.

\section{B. Identity and Territory}

Conflicts in the last two decades have also involved issues of identity and territory; conflict between Gamo and Welayita, Tigray and Amhara over welkayit, Amhara and Kimant, Silte and Gurage can be mentioned. Moreover, the new federal arrangement was also followed by territorial changes that led to claims and counter claims of territory and competition over shared resources $[3,26]$. This has also been a cause behind conflicts between Guji and Gedeo, Afar and Issa, Afar and Amhara and others.

C. Tensions in Majority and Minority Relations in Regional States

Though framers of ethnic federalism claimed that they have established nine regional states based on ethnicity, still majority of regional states host diverse nation nationalities in their territory. This needs another political arrangement at regional level to accommodate claims of ethnic groups, but is not an easy task. For instance, some regional states (BGRS ${ }^{13}$ and $\mathrm{GRS}^{14}$ ) categorized ethnic groups in to owners (titular) and non owners (non titular) in their constitution. Thus, the contradictory claims and counter claims of titular and non titular ethnic groups are sources of deadly ethnic conflicts in such regional states. Alem has stated, the new political arrangement has also forced previously dominant and dominated ethnic groups to adjust new forms of inter ethnic relations which in turn fuels ethnic conflicts [33], the case of Agew and Gumuz [12] and Guji and Gedeo are empirical examples. Contradictory interaction between majority and minority ethnic groups is another cause of inter ethnic conflicts.

Thus, though the Ethiopian government has adopted Ethnic federalism as a new approach to accommodate diversity since 1991, the recent condition of intra and inter ethnic affairs appear to challenge the long held interdependence and togetherness of the people in the country. Now a day people in different parts of the country are suffering from violent conflicts emanated from human fault lines, ethnicity and religion. However, the existing dynamics of ethnicity and ethnic conflicts in Ethiopia is not merely the result of ethnic federalism rather the interplay of
Movements).
13BenishangulGumuz Regional State
14Gambela Regional State 
various factors and it is contextual. Ethnic federalism is only a single factor among many others. But, it can be argued that ethnic federalism has decentralized conflict not power among ethnic identities of the country. Hence, understanding of ethnicity and ethnic relations in Ethiopia needs deep investigation in to historical and existing socio-political and economic contexts.

\section{Conclusions and Implications}

Indeed, Ethiopia is a heterogeneous state, the home for different ethnic, language and religious groups. This study reveals that the predominant schools of thought on ethnicity (primordialism and Instrumentalism) offer incomplete explanations to ethnicity and ethnic conflicts in the state. In Ethiopia, ethnicity is neither blindly primordial nor completely manipulable. Ethnicity is thus, a matter of categorical ascription and social organization in terms of culture and history, similarity and difference. Ethnicity in Ethiopia is an enormously complex concept. No ethnic entity has been untouched by others. Groups in existence in the twentieth century are biological and social amalgams of several preexisting entities. The ingredients are often discernible only by inference, particularly if the mixing took place long ago. Nonetheless, such mixing led to the formation of groups that think of themselves and are considered by others as different.

Ethiopia has also been experiencing the most deadly intra state conflicts - history of Ethiopia is history of conflicts. Accordingly, with the coming of EPRDF to political power in 1991, ethnicity is formalized as instrument of state organization to positively address the past intra state conflicts and ethnic inequality. However, despite the adoption of ethnic federalism as panacea to inter ethnic problems, the recent inter and intra ethnic affair in the state appears to challenge interdependence and togetherness of people.

As it has been discussed, ethnic conflicts in the state are not merely out of primordial differences or mobilization by ethnic entrepreneurs. Ethnic federalism is not also the only factor to be blamed for all evils undergoing in the state. But, conflicts in the country are results of feelings and sentiments in which members of a particular group develop as they interact and compare their positions with other ethnic groups. Still, the state lags behind in addressing old age questions of equality and fair distribution of resources. The new Prime Minister shall give emphasis to avoid one ethnic dominance over others in key activities of the state. Otherwise, the same problem keeps going and undermines the unity of the country. People are becoming more and more ethnic conscious each day, the government must be actively engaged in alleviating feeling of deprivation and exclusion among member ethnic groups of the state. New political instruments shall also be invented to accommodate the interest of minorities at regional level.

\section{References}

[1] TeshaleTibebu (1995). The Making of Modern Ethiopia (1896-1974). The Red SeaPress, Inc.

[2] Markakis, J. (2003). Ethnic Conflict in Pre Federal Ethiopia. $1^{\text {st }}$ NationalConference on Federalism, Conflict and Peace Building, May 5 - 7, 2003, Addis Ababa

[3] Hizkias Assefa (1996). Ethnic Conflict in the Horn of Africa: Myth and Reality. InKumar, R and A. T. Valery (eds), Ethnicity and Power in the ContemporaryWorld. Tokyo, New York, Paris: United Nations University Press.

[4] Endrias Eshete (2003). Ethnic Federalism: New Frontier in Ethiopian politics. $1^{\text {st }}$ NationalConference on Federalism, Conflict and Peace Building. May 5 - 7, 2003Addis Ababa.

[5] Desalegn Amsalu (2010). Awi- Gumuz relations: The Dynamics of Ethnicity in Ethiopia. Saarbruccken:VDMVeragDr. Mueller.

[6] Mengesha Emzat (2008). Federalism and Accommodation of Ethnic Diversity in Africa: The Ethiopian Experience. In The Kenyan Section of the International Commission of jurists, Ethnicity, Human Rights and Constitutionalism in Africa.

[7] Gebre Ab Barnabas (2003). Ethnic and Religious Policies of FDR Ethiopia. $1^{\text {st }}$ NationalConference on Federalism, Conflict and Peace Building. May 5 - 7, 2003Addis Ababa.

[8] Abbink, J. (1997). Ethnicity and Constitutionalism in Contemporary Ethiopia. Journal of African Law, 41, 159-174.

[9] Alemante Gebresellasie (2003). Ethnic Federalism: Its Promise and Pitfalls for Africa. Faculty Publications. Paper 88. http://scholarship.law.wm.edu./facbups/88.

[10] Mesfin Woldemariam (2004). YekhidetKulikulet. Nigid Printing Press.(Document in Amharic.

[11] Agbu, A. (2011) Ethnicity andDemocratizationin Africa:Challenges for Politics and Development. Discussion Paper 62, Nordiska Afrikainstitutet, Uppsala.

[12] Dagnachew Ayenew (2018). Relative Deprivation: an Explanation to Inter Ethnic Conflicts in Metekel Zone, North Western Ethiopia, Since 1991. IJPDS, Vol 9 (1-14).

[13] Tronvoll, K. (2002). Identities in Conflict: An ethnography of war and the politics of identity in Ethiopia1998-2000.(PhD dissertation, University of London).

[14] Merera Gudina(2006). Contradictory Interpretations of Ethiopian History: The Need for a new consensus. InTurton, D (ed), Ethnic Federalism: The EthiopianExperience in Comparative Perspective. Addis Ababa: A. A. U. Printing Press.

[15] Assefa Tolera (1995). Ethnic Integration and Conflict: The Case of indigenous Oromo and Amhara Settlers In Aaro Addis Alem, Kiramu Area, North western Wallaga. (MA Thesis, AAU)

[16] Wan, and Vanderwerf (2009). A Review of the Literature onEthnicity and National identity and Related MusicologicalStudies. available at www.GlobalMissiology.org accessed (November 4, 2015). 
[17] Dagnachew Ayenew (2016). Ethnicity and Inter Ethnic Relations between Agew and Gumuz in Post 1991 Ethiopia: The Case Metekel Zone. MA thesis, Bahirdar University

[18] Vaughan, S. (2003). Ethnicity and power in Ethiopia ( $\mathrm{PhD}$ thesis, University of Edinburgh) Retrieved (November 17, 2015) From http://www.era.lib.ed.ac.uk/ bitstream/1842/605/2/vaughanphd.pdf

[19] Wolf, S. (2006). Ethnic Conflict: A Global Perspective. Oxford: Oxford University Press.

[20] Freeman, D. (2005). An explanation of conflict: Ethnicity, Deprivation, and Rationalization. Paper presented at Kentucky Political Science Association Conference, Dr. Lori HartmannMahmud, 4 March 2005

[21] Hyden, G. (2006). African Politics in Comparative Perspective. Cambridge: Cambridge University Press.

[22] Eriksen, T. H. (2002). Ethnicity and Nationalism: Anthropological Perspectives. London: Pluto Press.

[23] Barth, F. (1969). Introduction. In Barth, F (ed), Ethnic Groups and Boundaries: theSocial organization of Culture Difference. Boston:Little, brown and company.

[24] Tegegne Teka(1998). Amhara Ethnicity in the Making. In Mohammed, Salihand Markakis, J (eds.) Ethnicity and the State in Eastern Africa. Uppsala:Nordic Africa Institute.

[25] Tsega Endalew (2006). Inter ethnic interaction on Frontier: Mettekel (Ethiopia), 1898-1991. Germanny: Otto harasowitiz and Co. KG. wiesebadin.
[26] Asnake Kefale (2013). Federalism and Ethnic Conflict in Ethiopia: A Comparative Regional Study. Newyork: Routledge.

[27] Gurr, TR (1970). Why Men Rebel. Princeton and NG: Princeton University Press.

[28] Clapham, C. (1990). The political economy of conflict in the Horn of Africa. Survival. 32 (5), 403-419.

[29] Wubshet Tsige (2015). Ankets 39: Yerasin Edil Beras mewosen - Tarik, Filsfina, Hig, Politika. Addis Ababa. (Document in Amharic).

[30] Bahiru Zewdie (2008). Society, State and History: selected essays. Addis Ababa: Addis Ababa University Press.

[31] Asafa Jalata (2010). The Ethiopian State: Authoritarianism, Violence and Clandestine Genocide. The Journal of Pan African Studies, 3 (6), 160-189.

[32] Merera Gudina (2003). Ethiopia: Competing Ethnic Nationalisms and the Quest forDemocracy, 1960-2000. Ethiopia: Chamber Printing House.

[33] Alem Habtu (2003). Ethnic Federalism in Ethiopia: Background, Present Conditions andFuture Prospects. Paper submitted to the second EAF International symposium On Contemporary Development Issues in Ethiopia. Addis Ababa. 